\author{
А.В. Дубовая ${ }^{1}$, Б.И. Кривущев ${ }^{1}$, Ю.В. Науменко ${ }^{1}$, О.О. Федотова ${ }^{2}$ \\ ${ }^{1} Г 00$ ВПО «Донецкий национальный медицинский университет имени М. Горького», Донецк \\ ${ }^{2}$ Республиканский специализированный центр медицинской генетики и пренатальной диагностики, Донецк
}

\title{
АМИНОКИСЛОТНЫЙ СОСТАВ КРОВИ И МОЧИ У ДЕТЕЙ С ЭССЕНЦИАЛЬНОЙ АРТЕРИАЛЬНОЙ ГИПЕРТЕНЗИЕЙ
}

Аминокислоты - органические вещества, содержащие карбоксильные и аминные группы. Известно около 100 аминокислот, но в синтезе белка участвуют только 20. Данные аминокислоты называются «протеиногенными» (стандартными) и по возможности синтеза в организме классифицируются на заменимые и незаменимые. [1]. К незаменимым аминокислотам относятся аргинин, валин, гистидин, изолейцин, лейцин, лизин, метионин, треонин, триптофан, фенилаланин. Заменимыми аминокислотами являются аланин, аспарагин, аспартат, глицин, глутамат, глутамин, пролин, серин, тирозин, цистеин. Протеиногенные и нестандартные аминокислоты, их метаболиты участвуют в различных обменных процессах в организме [4]. К гликогенным аминокислотам относятся те аминокислоты, при катаболизме которых образуются непосредственные предшественники глюкозы, вовлекаемые в процесс глюконеогенеза - пируват, оксалоацетат, фосфоеноилпируват (таких аминокислот 14), либо в жиры (кетогенные, одна аминокислота), либо и в углеводы, и в жиры (гликогенные и кетогенные, 5 аминокислот). Дефект ферментов на различных этапах трансформации веществ может приводить к накоплению аминокислот и их продуктов превращения, оказывать отрицательное влияние на состояние организма [5]. К факторам, обусловливающим изменение спектра аминокислот крови при артериальной гипертензии, относится интенсификация белкового обмена, наступающая в связи с гиперфункцией некоторых подкорково-корковых структур, сердечнососудистой системы, надпочечных желез, печени и почек [6-8]. Причиной нарушения белкового обмена при артериальной гипертензии является гипоксия и ацидоз, усиливающиеся при избытке катехоламинов. Среди факторов повышенного риска возникновения АГ и сердечнососудистых заболеваний особое внимание обращено и на роль гомоцистеина $[2,3]$. Гомоцистеин является наиболее значимым метаболи- ческим фактором, способным привести к развитию осложнений у подростков с эссенциальной артериальной гипертензией (АГ). Изменения аминокислотного профиля при сердечнососудистых заболеваниях проявляются на ранних стадиях и могут иметь прогностическое значение [9].

Цель: оценить аминокислотный состав крови и мочи у детей с эссенциальной артериальной гипертензией.

\section{МАТЕРИАЛ И МЕТОДЫ}

Под нашим наблюдением находились 20 детей (14 мальчиков и 6 девочек) в возрасте от 13 до 17 лет с диагнозом эссенциальная артериальная гипертензия. Исследование аминокислот крови и мочи выполнялось методом тонкослойной хроматографии на пластинах отечественных и зарубежных производителей: «Сорбфил» (Россия) и «Махерей Нагель» (Германия).

\section{РЕЗУЛЬТАТЫ ИССЛЕДОВАНИЯ}

В сыворотке крови и в моче у всех детей с эссенциальной артериальной гипертензией обнаружено повышение уровня валина. Предполагаем, что данные изменения связаны с нарушением биосинтеза аминокислот в печени, их мембранного транспорта. В крови и моче отмечено увеличение содержания тирозина у 7 (35\%) подростков, фенилаланина - у 6 (30\%) детей, глицина - у 3 (15\%) пациентов, треонина - у 2 (10\%) детей, серина - у 2 (10\%) пациентов. Уровень гомоцистеина у всех детей с эссенциальной АГ находился в пределах нормы.

Приводим собственное клиническое наблюдение.

Пациент Р. 16 лет, при поступлении в отделение детской кардиологии и кардиохирургии ИНВХ им. B.К. Гусака предъявлял жалобы на повышение арте-

(c) А.В. Дубовая, Б.И. Кривущев, Ю.В. Науменко,

О.О. Федотова, 2020

(c) Университетская Клиника, 2020 
риального давления до 200/120 мм рт. ст, иногда до 150/100 мм рт. ст., головную боль в височной области пульсирующего характера. Из анамнеза заболевания ребенка известно, что в течение последних 4 лет регистрируется повышенное артериальное давление (140-150/90 мм рт. ст.), головная боль в душном помещении. Не обследован. В ноябре 2019 года утром после пробуждения появилась головная боль в височной области, после подъема с постели появилась слабость, головокружение, «мелькание мушек» перед глазами, затем отмечался приступ потери сознания с судорожными подергиваниями конечностей, зарегистрированы цифры АД 200/110 мм рт. ст. Вызвана бригада скорой медицинской помощи (СМП), бессознательный период точно указать не могут (со слов мамы, был без сознания до приезда СМП). Госпитализирован в стационар с диагнозом: «Транзиторное нарушение мозгового кровообращения? Гипертонический криз».

Ребенок от I беременности, протекавшей без особенностей, I срочных физиологических родов. Масса тела при рождении 3400 г. Рос и развивался в соответствии с возрастом. Семейный анамнез отягощен: хронический пиелонефрит у матери, гипертоническая болезнь у отца с 18-летнего возраста.

При поступлении в стационар: состояние средней степени тяжести, обусловлено основным заболеванием. Правильного телосложения, удовлетворительного питания. Физическое развитие выше среднего, дисгармоничное за счет высокого роста. Эмоционально лабилен. Агрессивен. Кожные покровы смуглые, чистые. Слизистая ротовой полости чистая, розовая. Язык у корня обложен белым налетом. Дыхание в легких везикулярное. Тоны сердца ритмичные, умеренно приглушенные. ЧСС - 81 в минуту, АД - 130/80 мм рт. ст. Живот мягкий, безболезненный. Печень у края реберной дуги, селезенка не пальпируются. Стул, мочеиспускание в норме.

В клиническом анализе крови, биохимическом анализе крови патологических изменений не выявлено.

В клиническом анализе мочи без патологических изменений.

Тиреоидная панель (АТ к ТПО, ТТГ, Т4св.) в пределах нормы.

Липидограмма: триглицериды, общий холестерин, липопротеиды высокой плотности, липопротеиды низкой плотности - без патологических изменений.

Электролиты крови (калий, натрий, общий кальций) - в норме.

Адреналин, норадреналин, альдостерон, дофамин - в пределах нормы.

Биохимическое селективное скринирующее исследование аминокислотного состава крови и мочи: увеличение содержания валина, тирозина, фенилаланина, лейцина.

ЭхоКГ: камеры сердца не расширены. Формируется гипертрофия миокарда левого желудочка, толщина стенок в диастолу 1,14/1,17. Сократимость с гиперкинезом. ФВ - $77 \%$.

Суточное мониторирование артериального давления и холтеровское мониторирование электрокардиограммы: в течение времени наблюдения регистрировался синусовый ритм. ЧСС в течение суток в пределах возрастной нормы. ЧСС днем средняя - 100 в минуту, ЧСС днем минимальная - 60 в минуту, ЧСС ночью средняя - 61 у в минуту, ЧСС ночью минимальная - 51 в минуту. Циркадный индекс - 1,63 (в норме). В течение суток субмаксимальная ЧСС достигнута (83\% от максимально возможной для данного возраста). Ишемические изменения ЭКГ не обнаружены. Толерантность к нагрузке «средняя». Нагрузка не привела к возникновению ишемических изменений ЭКГ. Значимых изменений QT-интервала в течение суток не выявлено. Вариабельность ритма сердца сохранена. Соотношение высокочастотного и низкочастотного компонентов сбалансировано. Цифры диастолического АД днем характерны для гипотензии. Цифры систолического АД днем в пределах нормы. Цифры диастолического АД ночью в пределах нормы. По цифрам систолического АД ночью можно предположить гипертензию. «Индексы нагрузки давлением» систолического АД днем в пределах нормы. «Индексы нагрузки давлением» систолического АД ночью характерны для гипертензии (индекс гипертензии - 58\%). Циркадный индекс систолического АД - 8\%. Циркадный индекс диастолического АД 12\%. Снижение систолического АД ночью недостаточное. Снижение диастолического АД ночью в пределах нормы. Вариабельность систолического и диастолического АД в течение суток в пределах нормы.

Ультразвуковое исследование надпочечников: в проекции надпочечников дополнительных образований не выявлено. Визуализируется левый надпочечник размеров 18х16 мм, однородной структуры.

По данным мультисрезовой компьютерной томографии объемная и очаговая патология головного мозга не выявлена.

МРТ головного мозга с ангиографией: описаны изменения гипофиза, которые могут быть обусловлены кистой кармана Ратке с мукоидным содержимым либо последствиями перенесенного ранее процесса (в виде обызвествления?), микроаденома менее вероятна, изменения требуют наблюдения.

Дуплексное сканирование сосудов почек: эхопризнаки добавочного верхне-полярного сосуда справа. Выявлены гемодинамически значимые нарушения кровотока в почках: высокие линейные скорости кровотока и повышенные индексы сопротивления.

Мальчик консультирован ангиохирургом: добавочная артерия правой почки. Показано проведение ангиографии сосудов почек.

Ангиография почечных артерий: гемодинамически значимого окклюзионно-стенотического поражения не выявлено. 
Консультация окулиста: на глазном дне сужены артерии. ДЗН ровные, границы четкие. Смешанный астигматизм, ангиопатия сетчатки OU.

Консультация нейрохирурга: рекомендованы МРТ-контроль через 6-12 мес., консультация эндокринолога, невролога, прием антиконвульсантов.

Осмотрен эндокринологом: на момент осмотра данных в пользу патологии щитовидной железы, надпочечников у ребенка нет.

На основании данных лабораторных и инструментальных методов исследования ребенку выставлен диагноз: эссенциальная артериальная гипертензия, 2 степень, высокий риск. Кистома кармана Ратке. Вторичный генез артериальной гипертензии исключен после проведения вышеперечисленных обследований.

Ребенку назначена антигипертензивная, седативная терапия.

За время нахождения в стационаре состояние ребенка удовлетворительное. Эмоциональный фон нормализовался. Проявления агрессии уменьшились. Цифры артериального давления находились в пределах возрастной нормы: 110-120/80-70 мм рт. ст. Ребенок с рекомендациями выписан из стационара для дальнейшего амбулаторного наблюдения.

На фоне ранее назначенной терапии через 1 месяц от начала лечения жалоб на повышение АД, головную боль не отмечалось. Продолжает получать антигипертензивную, седативную, кардиотрофическую терапию.
Анализируя данный клинический случай, можно предположить, что изменения гликогенных и кетогенных аминокислот у данного пациента происходят, главным образом, за счет влияния психоэмоциональных факторов при преобладании симпатической нервной системы, вследствие чего в печени, сердце, головном мозге и других тканях увеличивается потребность в аминокислотах, которые расходуются на синтез белков, обеспечивающих развитие гиперфункции и компенсаторной гипертрофии миокарда и других приспособительных реакций организма. При этом активируется генетический аппарат миокардиальных клеток и свободные аминокислоты используются миокардом для увеличения синтеза белка, нуклеиновых кислот и развития компенсаторной гипертрофии миокарда, направленной на предупреждение его недостаточности.

\section{З АК ЛЮЧЕНИЕ}

Аминокислотный профиль плазмы крови пациентов с эссенциальной артериальной гипертензией характеризуется повышением уровней валина, тирозина, фенилаланина, глицина, серина. Представленный клинический случай демонстрирует, что изменения аминокислотного профиля при эссенциальной артериальной гипертензии проявляются на ранних стадиях и могут иметь прогностическое значение.

\section{А.В. Дубовая ${ }^{1}$, Б.И. Кривущев ${ }^{1}$, Ю.В. Науменко ${ }^{1}$, О.О. Федотова ${ }^{2}$ \\ ${ }^{1}$ ГОО ВПО «Донецикий национальный медицинский университет имени М. Горького», Донецк \\ ${ }^{2}$ Республиканский специализированный центр медицинской генетики и пренатальной диагностики, Донецк}

\section{АМИНОКИСЛОТНЫЙ СОСТАВ КРОВИ И МОЧИ У ДЕТЕЙ С ЭССЕНЦИАЛЬНОЙ АРТЕРИАЛЬНОЙ ГИПЕРТЕНЗИЕЙ}

Проблема артериальной гипертензии в педиатрической практике в последние десятилетия становится более актуальной в связи с возрастающей частотой повышения артериального давления, торпидности к проводимой терапии, риском развития осложнений. В статье представлены изменения аминокислотного состава крови и мочи у детей с эссенциальной артериальной гипертензией. Аминокислотный профиль плазмы крови и мочи пациентов с эссенциальной артериальной гипертензией характеризовался повыше- нием уровней валина, тирозина, фенилаланина, глицина, серина. Представлен клинический случай, демонстрирующий увеличение содержания валина, тирозина, фенилаланина, лейцина у пациента с эссенциальной артериальной гипертензией. Изменения аминокислотного профиля при эссенциальной артериальной гипертензии проявляются на ранних стадиях и могут иметь прогностическое значение.

Ключевые слова: аминокислоты, дети, эссенциальная артериальная гипертензия. 


\section{A.V. Dubovaya ${ }^{1}$, B.I. Krivuschev ${ }^{1}$, Yu.V. Naumenko ${ }^{1}$, O.O Fedotova ${ }^{2}$}

${ }^{1}$ SEI HPE «M. Gorky Donetsk National Medical University», Donetsk

${ }^{2}$ Republican specialized center for medical genetics and prenatal diagnosis, Donetsk

\section{AMINO ACID COMPOSITION OF BLOOD AND URINE IN CHILDREN WITH ESSENTIAL ARTERIAL HYPERTENSION}

The problem of arterial hypertension in pediatric practice has become in recent decades more relevant in connection with the increasing frequency of increased blood pressure, torpidity to therapy and the risk of complications. The article presents changes in the amino acid composition of blood and urine in children with essential arterial hypertension. The amino acid profile of the blood plasma and urine of patients with essential arterial hypertension was characterized by an increase in the lev- els of valine, tyrosine, phenylalanine, glycine, and serine. A clinical case is presented, demonstrating an increase in the content of valine, tyrosine, phenylalanine, leucine in a patient with essential arterial hypertension. Changes in the amino acid profile with essential arterial hypertension appear in the early stages and may have prognostic value.

Key words: amino acids, children, essential arterial hypertension.

\section{ЛИТЕРАТУРА}

1. Kume S. Predictive properties of plasma amino acid profile for cardiovascular disease in patients with type 2 diabetes. PLoS One. 2014; 6: e101219. doi: 10.1371/journal. pone. 0101219

2. Спиридонова М.Г., Степанов В.А., Пузырев В.П. O роли полиморфных вариантов гена 5,10метилентетрагидрофолатредуктазы (MTHFR) в патогенезе сердечно-сосудистых заболеваний. Клин. мед. 2015; $2: 10-16$.

3. Кирхнер Ю. Тонкослойная хроматография. М.: Мир; 1981.612 .

4. Рыбакова К.Д., Кузьмичева Н.А. Биохимические методы диагностики наследственных болезней: учебное пособие. М.; 1984. 27.

5. Краснопольской К.Д. Методические рекомендации по выявлению наследственных дефектов обмена. М.;1985: 18-19.

6. Калинин О.В. Специфические функции незаменимых аминокислот. Молодежь и наука. 2016; $1: 2$.

7. Левчук Л.В., Бородулина Т.В., Санникова Н.Е., Данилова И.Г. Клиническое значение содержания свободных аминокислот для роста и развития детей. Уральский медицинский журнал. 2017; 5 (149): 11-15.

8. Литвицкий П.Ф., Мальцева Л.Д. Нарушения обмена белков, аминокислот и нуклеиновых кислот. Вопросы современной педиатрии. 2015; 14 (1): 95-107.

9. Никитина О.Е., Наумов А.В., Дорошенко Е.М., Снежицкий В.А. Особенности спектра серосодержащих аминокислот и их производных у пациентов с артериальной гипертензией в зависимости от параметров геометрического ремоделирования левого желудочка. Журнал Гродненского государственного медицинского университета. 2015; 1 (49): 49-55.

\section{REFERENCES}

1. Kume S. Predictive properties of plasma amino acid profile for cardiovascular disease in patients with type 2 diabetes. PLoS One. 2014; 6: e101219. doi: 10.1371/journal. pone. 0101219

2. Spiridonova M.G., Stepanov V.A., Puzyrev V.P. O roli polimorfnykh variantov gena 5,10-metilentetragidrofolatreduktazy (MTHFR) v patogeneze serdechno-sosudistykh zabolevanii. Klin. med. 2015; 2: 10-16 (in Russian).

3. Kirkhner Yu. Tonkosloinaya khromatografiya. M.: Mir; 1981. 612 (in Russian).

4. Rybakova K.D., Kuz'micheva N.A. Biokhimicheskie metody diagnostiki nasledstvennykh boleznei: uchebnoe posobie. M.; 1984. 27 (in Russian).

5. Krasnopol'skoi K.D. Metodicheskie rekomendatsii po vyyavleniyu nasledstvennykh defektov obmena. M.;1985: 18-19 (in Russian).

6. Kalinin O.V. Spetsificheskie funktsii nezamenimykh aminokislot. Molodezh' i nauka. 2016; 1: 2 (in Russian).

7. Levchuk L.V., Borodulina T.V., Sannikova N.E., Danilova I.G. Klinicheskoe znachenie soderzhaniya svobodnykh aminokislot dlya rosta i razvitiya detei. Ural'skii meditsinskii zhurnal. 2017; 5 (149): 11-15 (in Russian).

8. Litvitskii P.F., Mal'tseva L.D. Narusheniya obmena belkov, aminokislot i nukleinovykh kislot. Voprosy sovremennoi pediatrii. 2015; 14 (1): 95-107 (in Russian).

9. Nikitina O.E., Naumov A.V., Doroshenko E.M., Snezhitskii V.A. Osobennosti spektra serosoderzhashchikh aminokislot i ikh proizvodnykh u patsientov s arterial'noi gipertenziei v zavisimosti ot parametrov geometricheskogo remodelirovaniya levogo zheludochka. Zhurnal Grodnenskogo gosudarstvennogo meditsinskogo universiteta. 2015; 1 (49): 49-55 (in Russian). 